\title{
Mitigation of salt induced stress via arbuscular mycorrhizal fungi (Rhizophagus irregularis) inoculation in Cucurbita maxima Duch
}

\begin{abstract}
It has been projected that about $7 \%$ of the earth's agricultural land is exposed to extreme soil salinity levels. High presence of salts in soil reduces plant water content and nutrient uptake thereby disrupting the dissemination of ions at both the cellular and the wholeplant levels, ultimately inducing osmotic and ionic disparities. The current research was carried out to examine the role of arbuscular mycorrhizal fungi (Rhizophagus irregularis) in alleviating adverse effects of salt stress in Cucurbita maxima. Physicochemical properties of the experimental soils analysis (saline and garden soils) indicated significant $(\mathrm{p}=0.05$ ) differences between the two soil types in; $\mathrm{pH}$, total nitrogen, available phosphorus, Ex. Ca, Ex. Mg, Ex. K, OC, Ex. Na and EC. Saline soil treatment significantly $(p=0.05)$ reduced photosynthetic pigments contents (chlorophyll a, b and carotenoids), minerals ( $, \mathrm{P}, \mathrm{K}, \mathrm{Mg}$ and $\mathrm{Ca}$ ), leaf relative water content (LRWC), shoot length, dry weight as well as percentage arbuscular mycorrhizal fungi colonization (45.45 to $20.34 \%$ ) and mycorrhizal dependency $(100.00 \%$ to $13.87 \%)$. The effects of mycorrhizal symbiotic association on Cucurbita maxima showed improvements on the growth and physiology of Cucurbita maxima. Using different mechanisms Cucurbita maxima by itself or in association with arbuscular mycorrhizal fungi (Rhizophagus irregularis) can tolerate or survive soil salinity. However, symbiotic association of the fungus $R$. irregularis with roots of Cucurbita maxima gives the plant the ability to resist the stress as a result of morphological and physiological vicissitudes and improved vigour/water content, adjusted rate of $\mathrm{K}^{+} / \mathrm{Na}^{+}$, extensive network of the mycorrhizal plant roots and enhanced nutrient uptake are all among the processes that made the mycorrhizal inoculated plant to survive under severe salt stress conditions.
\end{abstract}

Volume 4 Issue I - 2019

\author{
Okon Okon G,' Okon Iniobong E, ${ }^{2}$ Mbong \\ Emem O, ${ }^{3}$ Eneh Grace DO ${ }^{4}$ \\ 'Department of Biological Sciences, Ritman University, Nigeria \\ ${ }^{2}$ Department of Botany and Ecological Studies, University of \\ Uyo, Nigeria \\ ${ }^{3}$ Science Laboratory Technology Department, Heritage \\ Polytechnic, Nigeria \\ ${ }^{4}$ Department of Science Technology, Akwa Ibom State \\ Polytechnic, Nigeria
}

\begin{abstract}
Correspondence: Okon Okon G, Department of Biologica Sciences, Faculty of Natural and Applied Sciences, Ritman University, lkot Ekpene, Nigeria,
\end{abstract}

Email okonokongodwin@yahoo.com

Received: January 19, 2019 | Published: February 28, 2019

Keywords: cucurbitaceae, glomeraceae, mycorrhiza, salinity salt tolerance

\section{Introduction}

Soil solution is regarded as one of the best medium of plant growth and development because it contains various important soluble salts. ${ }^{1}$ A key threat to worldwide crop production is the build-up of salts in the soil. ${ }^{2,3}$ According to estimates, $7 \%$ world's agricultural lands are exposed to very high soil salinity levels. ${ }^{3}$ Thus, Salinity can be defined as the soil content of water-soluble salts, predominantly sodium, chloride, potassium, magnesium and calcium. When the electrical conductivity of a soil saturated paste extract (ECE) measures up to $4 \mathrm{dS} / \mathrm{m}$ or higher, which is comparable to $40 \mathrm{~mm} \mathrm{NaCl}$, are distinctive of saline soils. This definition of salinity is driven from the ECE that significantly reduces the yield of most crops. Under natural conditions, the salts in soil contaminated by sea water are usually mixtures of several cations and anions.

These soluble salts (such as; sodium, chloride, potassium, magnesium and calcium) in the soils are readily absorbed by roots of plants and translocate to the aerial and different plant parts where these salts are essential to performing several metabolic activities. Nevertheless, when these water-soluble salts are present in the soil in abundance, they inhibits plant water and nutrient ascent and consequently upset the proper dissemination of ions in the cellular and the whole-plant levels, thus prompting osmotic stress and ionic disproportions. ${ }^{1}$ This extreme and sudden change results in diminutive growth and development of plants mostly resulting in the death of the plant. The excessive accumulation of water-soluble salts such as $\mathrm{Na}^{+}$and $\mathrm{Cl}^{-}$in the tissues of plants results in oxidative mutilation (mostly regarded as secondary stress), the plant membranes integrity is severely damaged (damage to proteins, lipids and nucleic acids), marring the actions of biocatalysts and workings of chloroplast (photosynthetic apparatus), This can be attributed to the generation and lethal properties of reactive oxygen species (ROS) which are produced under soil salinity stress conditions. ${ }^{1,4,5}$

Beneficial microorganisms such as arbuscular mycorrhizal fungi (AMF) are capable of colonizing plants in their regular environment and in stressed environments. Some of these microorganisms are beneficial and has been observed to play important roles in the improvements of plant tolerance and performance especially in environments that experience abiotic stress thereby giving rise to improved crop production and yield. ${ }^{6}$ It has been reported that AM fungi forms association with about $80 \%$ land-dwelling plant species. ${ }^{7}$ Many researches has reported the beneficial effects of inoculating plants with AM fungi under saline soil conditions and its role in salinity tolerance under such conditions. AM fungi ubiquitous in the different ecosystem types ${ }^{3}$ and have been reported in extreme environments such as sub-polar regions, arid regions, tropical regions and even in aquatic ecosystems. ${ }^{8}$ The symbiotic association between plant and AM fungi are extremely antique and dates back to about 400 million years. ${ }^{3}$ Every plant species has its dissimilar degree of mycorrhizal dependency, example; Vicia faba (faba bean) is highly dependent on mycorrhizas and depends highly on its association for subsequent growth and establishment. ${ }^{9}$

Cucurbita maxima belong to the family Cucurbitaceae and is a climbing, annual, herbaceous vine, reaching a length of $4 \mathrm{~m}$ or more. Leaves are hispid, rounded, $15-30 \mathrm{~cm}$ in diameter, heart-shaped at the base, shallowly 5-lobed, with finely toothed margins, and often mottled on the upper surface. Flowers are bell-shaped, erect, yellow 
and about 12 centimetres long. Fruit is large, variable in shape, fleshy, with a yellow pulp. Seeds are ovoid or oblong, compressed, and about 1.3 centimetres long. ${ }^{10}$ C. maxima varieties are used for preparation of many dishes. In Cameroon, Nigeria and other Western African countries, seeds of C. maxima are widely used as a vegetable, roasted and salted, or ground into a thick paste that is mixed with vegetables in cooking. ${ }^{11}$ The medicinal uses of $C$. maxima include the dried pulp, in the form of confection, used as remedy for hemoptysis and hemorrhages from the pulmonary tract. ${ }^{10}$

Rhizophagus irregularis belongs to the family Glomeraceae. Spores colour of Rhizophagus irregularis is white, cream, and yellow-brown. Shape is elliptical with irregularities. Size is generally between $40-140 \mu \mathrm{m}$, Hyphae shape is Cylindrical or slightly flared. ${ }^{12}$ Size-Width: $11-18 \mu \mathrm{m}$. In numerous scientific studies Rhizophagus irregularis has been publicized to increase phosphorus uptake in multiple plants as well as improve soil aggregation due to hyphae; because of these qualities, Rhizophagus irregularis is commonly found in mycorrhizal based fertilizers. Rhizophagus irregularis colonization peaks earlier than many of the other fungi in the Glomus genu..$^{12}$ There tends to be extensive hyphal networking and intense intraradical spores associated with older roots of host plants. At times the spores are densely clustered or patchily distributed, depending on the host species. When the spores are heavily clustered, mycorrhizologists and others will tend to mistake Rhizophagus irregularis for Glomus fasciculatum. ${ }^{12}$

\section{Materials and methods}

\section{Study area}

Saline soil and salt water were collected from the saline ecosystem of Iwuochang, Ibeno Local Government Area (Latitude $4.56^{\circ} \mathrm{N}$ and Longitude $7.57^{\circ} \mathrm{E}$ ), Akwa Ibom State, Nigeria, with an annual rainfall of about $4021 \mathrm{~mm}$ and mean temperature variation of $22-31^{\circ} \mathrm{C}$. The experiment was set up in a safe and secured environment at Mbioto 1, Etinan Local Government Area (Latitude $4.51^{\circ} \mathrm{N}$ and Longitude $\left.7.50^{\circ} \mathrm{E}\right)$, Akwa Ibom State, Nigeria, with an annual rainfall of about $4000 \mathrm{~mm}$ and mean temperature variation of $26-36^{\circ} \mathrm{C}$ (AKSG, 2008). Non-saline soil for the control and non-saline treatments was obtained from a farmland in Mbioto 1, Etinan Local Government Area; fresh water was used for watering the non-saline and control treatments. A map showing the saline water/soil collection and experimental set-up locations is presented in Figure 1 (Table 1).

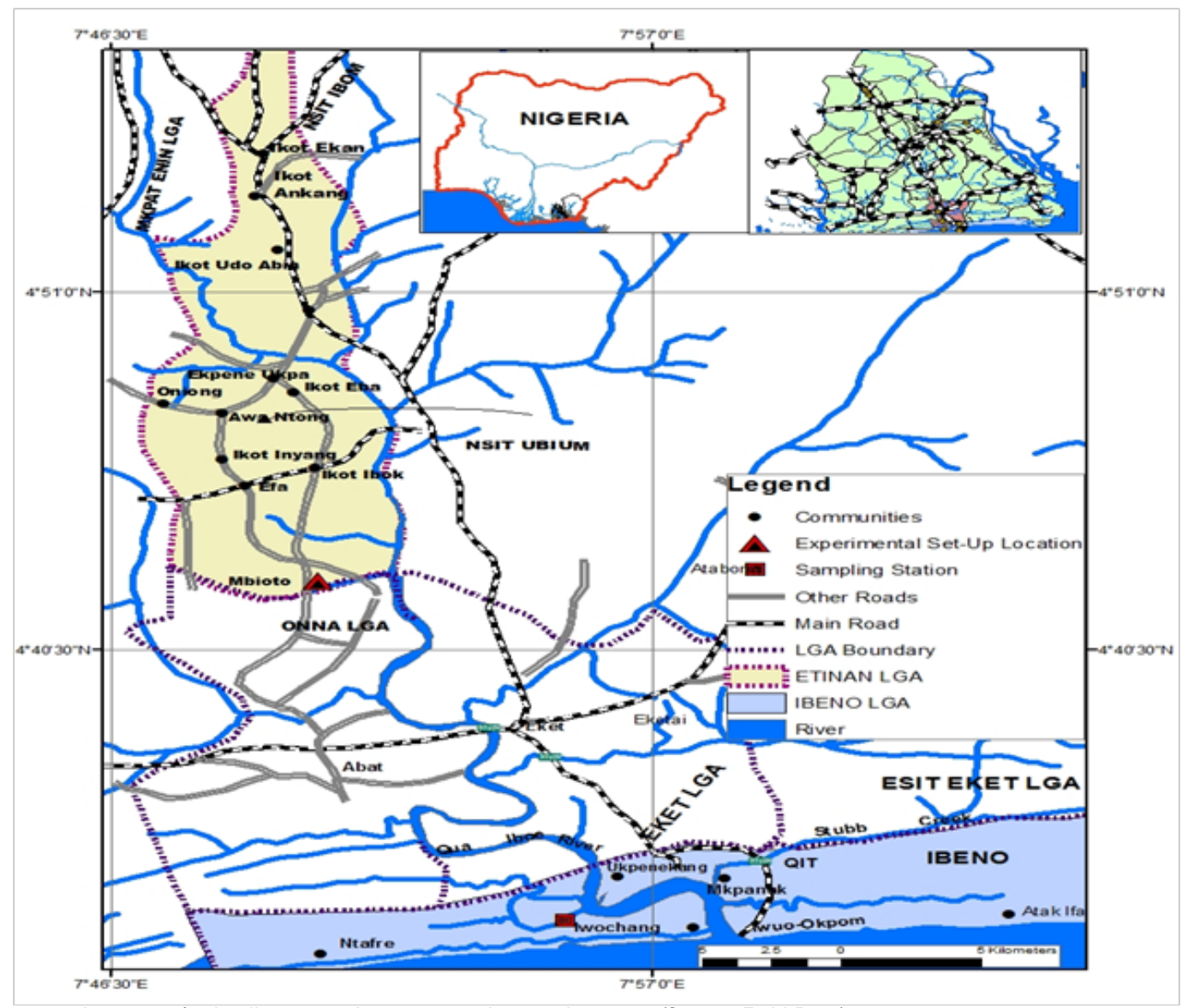

Figure I Map showing saline water/soil collection and experimental set-up locations (Source: Field Data).

\section{Source of arbuscular mycorrhizal (am) fungi}

The AM Fungi (Rhizophagus irregularis) inoculum used in this experiment (60-65 spores per $5 \mathrm{~g})$ was purchased from International Institute of Tropical Agriculture (IITA) Ibadan, Nigeria.

\section{Physico chemical properties of experimental soils}

The soil samples were taken and air-dried at room temperature and ground in a wooden mortar to pass through a $2 \mathrm{~mm}$ mesh sieve and stored in labelled bags. Sub-samples were taken from each soil 
sample and analyzed for physico-chemical properties of the soil. All soil analyses were carried out in the Soil Science Department of the University of Uyo, Uyo, Akwa Ibom State. Soil samples were analyzed following the standard procedures outlined by the Association of Official Analytical Chemist procedure for wet acid digestions. ${ }^{13}$

Table I Experimental design

\begin{tabular}{ll}
\hline Treatments & Meaning \\
\hline S- M- & - Salinity, - Mycorrhiza \\
S+M- & + Salinity, - Mycorrhiza \\
S + M+ & + Salinity, + Mycorrhiza (Rhizophagus irregularis) \\
S- M+ & - Salinity, + Mycorrhiza \\
\hline
\end{tabular}

\section{Estimation of photosynthetic pigments}

The photosynthetic pigments (such as chlorophyll a, chlorophyl $\mathrm{b}$ and carotenoids) were extracted from leaves of $C$. maxima plants using dimethyl sulfoxide (DMSO) as recommended. ${ }^{14}$ Absorbance was determined spectrophotometrically at $480,510,645$, and $663 \mathrm{~nm}$ (T80 UV/VIS Spectrometer, PG Instruments Ltd, USA). DMSO was used as blank.

\section{Determination of mineral content}

The plant samples were sent to Ministry of Science and Technology, Akwa Ibom State for mineral analysis. Mineral contents: Nitrogen (N) was determined using the Macro-Kjeldahl method while calcium $(\mathrm{Ca})$, magnesium $(\mathrm{Mg})$, potassium $(\mathrm{K})$, sodium $(\mathrm{Na})$ and phosphorus (P) of plant samples were determined by atomic absorption spectrophotometer (AAS), flame photometry and spectrophotometry according to the methods of AOAC..$^{15}$

\section{Determination of shoot length}

Measurement of shoot length was taken at nine (9) weeks after planting following seedling emergence using a measuring tape.

\section{Determination of leaf area}

Measurements were obtained using graph paper (grid method). The area (A) of the leaf was determined by tracing the outlines of the leaves on a standard graph paper. The area covered by the outline was then calculated (one small square on the graph represents $1 \mathrm{~cm}^{2}$ ). The correlation factor $(\mathrm{K})$ was determined by dividing the area $(\mathrm{A})$ by product of length $\mathrm{x}$ breadth of the leaf. Thereafter, the leaf area for each plant was determined using the formula:

$$
\mathrm{A}=\mathrm{L} \times \mathrm{B} \times \mathrm{K}
$$

Where: $\mathrm{A}=$ the traced area, $\mathrm{L}=$ Leaf length, $\mathrm{B}=\mathrm{Leaf}$ width, $\mathrm{K}=$ Correction factor

\section{Determination of leaf dry weight}

Leaf dry weight was determined after oven drying the leaves to constant weight at $70^{\circ} \mathrm{C}$

\section{Leaf relative water content}

Two (2) young fully expanded leaves were collected from about two plants per replicate. The leaves were detached from the stem and weighed to determine the fresh weight (FW). To determine the turgid weight (TW), leaves were floated in distilled water inside a closed petri dish. Leaf samples were weighed periodically after gently wiping the water from the leaf surface with tissue paper until a steady state was achieved. At the end of the imbibition period, leaf samples were placed in a preheated oven at $80^{\circ} \mathrm{C}$ for 48 hours to determine the dry weight (DW). Values of FW, TW, and DW were used to calculate LRWC using the formula (Kaya et al., 2003):

$$
\operatorname{LRWC}(\%)=\frac{(\mathrm{FW}-\mathrm{DW})}{\mathrm{TW}-\mathrm{DW}} \times 100
$$

\section{Quantification of arbuscular mycorrhizal colonization in plant roots}

Feeder roots of about $2-4 \mathrm{~cm}$ of $T$. occidentalis were separately collected, fixed in 50\% ethanol and stored for colonization assessment. The fixed roots were rinsed in tap water before clearing in $10 \%$ $\mathrm{KOHw} / \mathrm{v}$ and autoclaved for about 15 minutes at $121^{\circ} \mathrm{C}$. Cleared roots were collected on a fine sieve and rinsed with water several times before being transferred into the staining solution. Staining of the plants roots was carried out using 5\% ink diluted in vinegar $(5 \%$ acetic acid). The roots segments were soaked in the ink and left in staining solution at room temperature for one day. Stained roots were later destained in $50 \%$ glycerol for 1 hour. ${ }^{16}$

Stained roots were randomly dispersed in a $9 \mathrm{~cm}$ diameter Petri plate with grid lines. Vertical and horizontal gridlines were scanned at $\mathrm{x} 40$ magnification with a dissecting microscope. The proportion of root length that is mycorrhizal and total root length can then be calculated from a conversion factor derived from the total length of grid lines and the area of the dish. A minimum of 100 intersections was used to assess the stained root samples; the samples were rerandomized and counted several times. Mycorrhizal root colonization was thus determined by estimation of percentage of root segments containing hyphae, arbuscules and vesicles. ${ }^{17}$

$$
\begin{aligned}
& \mathrm{MC}=\frac{\text { Total number of roots infected intersecting gridlines }}{\text { Total number of roots intersecting gridlines }} \times 100 \\
& \text { Determination of mycorrhizal dependency }(\mathbf{m d})
\end{aligned}
$$

Mycorrhizal dependency (MD) was calculated according to the following formula:

$\mathrm{MD}=\frac{\text { DW inoculated Plants }- \text { DW non }- \text { inoculated Plants }}{\text { DW inoculated Plants }} \times 100$

\section{Statistical analysis}

The study was conducted using complete randomized design with three (3) replicates for each plant. All data in the present study were subjected to analysis of variance (ANOVA) using Statistical package for Social Sciences and data are presented as standard error of mean $( \pm$ S.E.M.) of triplicate experiments. The differences between the means were separated and compared using the Duncan's multiple range tests. However, a probability level of $\mathrm{p}=0.05$ was considered statistically significant.

\section{Results}

\section{Physicochemical properties of the experimental soils (saline and non-saline soil)}

The t-test analysis carried out on the physicochemical properties of the experimental soils (saline and garden soils) indicated significant $(\mathrm{p}=0.05)$ differences between the two soil types in; $\mathrm{pH}$, total nitrogen, available phosphorus, silt, clay, sand, Ex. Ca, Ex. Mg, Ex. K, OC, Ex. $\mathrm{Na}$ and EC. However, there was no significant $(\mathrm{p}=0.05)$ difference in Ex. Acidity, ECEC and base saturation (Table 2). 
Table 2 Physicochemical properties of the experimental soils

\begin{tabular}{|c|c|c|c|c|}
\hline S/No & Parameters & $\begin{array}{l}\text { Garden } \\
\text { soil }\end{array}$ & $\begin{array}{l}\text { Saline } \\
\text { soil }\end{array}$ & t-values \\
\hline I & $\mathrm{pH}$ & 6.78 & 7.75 & $-56.655^{*}$ \\
\hline 2 & Total Nitrogen (\%) & 2.27 & 0.49 & $6.928^{*}$ \\
\hline 3 & Available P. (mg/kg) & 36.31 & 24.66 & $663.929 *$ \\
\hline 4 & Silt (\%) & 4 & 5.6 & $-51.995^{*}$ \\
\hline 5 & Clay (\%) & 4.2 & 12 & $-193.742 *$ \\
\hline 6 & Sand (\%) & 92.04 & 82.4 & $261.909 *$ \\
\hline 7 & Ex. Ca (cmol./kg) & 5.25 & 2.97 & $-148.956 *$ \\
\hline 8 & Ex. Mg (cmol./kg) & 4.36 & 3.8 & $23.714 *$ \\
\hline 9 & Ex. Na. (cmol./kg) & $0.4 I$ & 8.81 & $1.000 *$ \\
\hline 10 & Ex. K. (cmol./kg) & 6.98 & 1.48 & $43.301 *$ \\
\hline II & Organic Carbon (\%) & 5.61 & 1.61 & $-599.00 *$ \\
\hline 12 & $\begin{array}{l}\text { Exchangeable acidity } \\
\text { (meq/l00g) }\end{array}$ & 3.56 & 3.2 & 20.785 \\
\hline 13 & ECEC (cmol./kg) & 20.56 & 20.26 & -228.669 \\
\hline 14 & Base saturation (\%) & 82.68 & 84.2 & $-64.34 I$ \\
\hline 15 & $\mathrm{EC}(\mathrm{dS} / \mathrm{m})$ & 0.32 & 7.8 & $-93.260 *$ \\
\hline
\end{tabular}

*Significant at $\mathrm{t}=0.05$, Ex, exchange; ECEC, effective cation exchange capacity; EC, electrical conductivity

Effect of arbuscular mycorrhizal fungi (amf) inoculation on the photosynthetic pigments of c. maxima grown in saline soil

The content of photosynthetic pigments of Cucurbita maxima (such as chlorophyll a, chlorophyll b and carotenoids) grown in saline soils taken at 9 WAP were significantly $(\mathrm{p}=0.05)$ reduced when compared to the control while inoculation with AMF (R. irregularis) significantly $(\mathrm{p}=0.05)$ increased these pigments in the test plant (Figure 2).

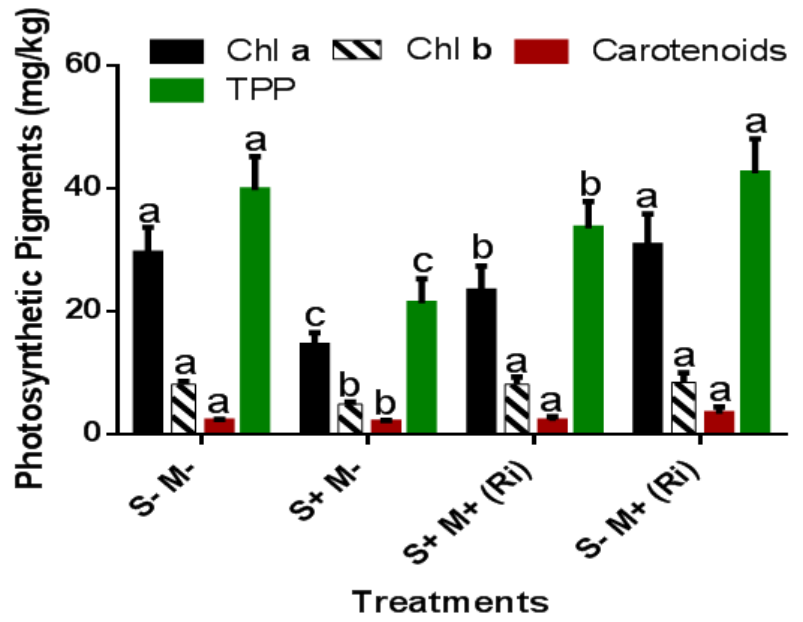

Figure 2 Effects of AMF inoculation on the photosynthetic pigments content

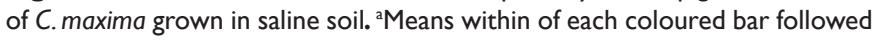
by different letters are significantly different at $\mathrm{p}=0.05$ according to Duncan's Multiple Range Test. S- (No salinity), M- (No mycorrhiza), S+ (Plus salinity), M+ (Plus mycorrhiza), (Ri) - Rhizophagus irregularis.

\section{Effect of arbuscular mycorrhizal fungi (amf) inoculation on the mineral nutrient contents and biomass yield of c. maxima grown in saline soil}

Mineral nutrient contents of $C$. maxima $\mathrm{P}, \mathrm{K}, \mathrm{Mg}$ and $\mathrm{Ca}$ were significantly $(\mathrm{p}=0.05)$ reduced in saline soil treatments when compared to the control while, $\mathrm{N}$ showed slight decrease in saline soil treatments, while $\mathrm{Na}$ increased in saline soil treatments (Table 3). Inoculation with AMF (Rhizophagus irregularis) significantly $(\mathrm{p}=0.05)$ increased the mineral nutrient contents, leaf relative water content and biomass yield in the test plant in saline and non-saline soil treatments (Table 3).

Table 3 Effects of arbuscular mycorrhizal fungi (AMF) inoculation on the mineral nutrient contents of $C$. maxima grown in saline soil

\begin{tabular}{lllll}
\hline Parameters & S- M- & $\begin{array}{l}\text { S+ } \\
\text { M- }\end{array}$ & S+ M+ (Ri) & S- M+ (Ri) \\
\hline $\mathrm{N}(\%)$ & $* 5.03^{\mathrm{a}}$ & 0 & $3.44^{\mathrm{b}}$ & $5.28^{\mathrm{a}}$ \\
$\mathrm{P}(\mathrm{mg} / \mathrm{kg})$ & $754.10^{\mathrm{b}}$ & 0 & $510.10^{\mathrm{c}}$ & $894.40^{\mathrm{a}}$ \\
$\mathrm{K}(\mathrm{mg} / \mathrm{kg})$ & $4610.10^{\mathrm{b}}$ & 0 & $2215.10^{\mathrm{c}}$ & $4811.10^{\mathrm{a}}$ \\
$\mathrm{Mg}(\mathrm{mg} / \mathrm{kg})$ & $560.14^{\mathrm{b}}$ & 0 & $418.00^{\mathrm{c}}$ & $601.10^{\mathrm{a}}$ \\
$\mathrm{Ca}(\mathrm{mg} / \mathrm{kg})$ & $3008.10^{\mathrm{b}}$ & 0 & $1620.20^{\mathrm{c}}$ & $3240.00^{\mathrm{a}}$ \\
$\mathrm{Na}(\mathrm{mg} / \mathrm{kg})$ & $387.70^{\mathrm{a}}$ & 0 & $1320.20^{\mathrm{c}}$ & $309.10^{\mathrm{b}}$ \\
$\mathrm{Na}+\mathrm{K}+$ ratio & $0.08^{\mathrm{b}}$ & 0 & $0.59^{\mathrm{a}}$ & $0.06^{\mathrm{b}}$ \\
$\begin{array}{l}\text { Leaf Area (cm2) } \\
\text { Shoot Length }\end{array}$ & $56.21 \pm 0.72^{\mathrm{b}}$ & 0 & $25.44 \pm 1.32^{\mathrm{c}}$ & $60.31 \pm 1.12^{\mathrm{a}}$ \\
$(\mathrm{cm})$ & $54.61 \pm 3.99^{\mathrm{a}}$ & 0 & $17.73 \pm 0.45^{\mathrm{b}}$ & $59.76 \pm 2.13^{\mathrm{a}}$ \\
$\begin{array}{l}\text { Leaf Relative } \\
\text { Water Content } \\
\text { (LRWC) (\%) }\end{array}$ & $38.00 \pm 2.51^{\mathrm{a}}$ & 0 & $36.36 \pm 1.66^{\mathrm{b}}$ & $42.65 \pm 1.57^{\mathrm{a}}$ \\
$\begin{array}{l}\text { Total Dry Weight } \\
\text { (gplant-1) }\end{array}$ & $4.06^{\mathrm{a}}$ & 0 & $1.18^{\mathrm{b}}$ & $4.43^{\mathrm{a}}$ \\
\hline
\end{tabular}

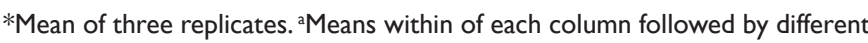
letters are significantly different at $\mathrm{p}=0.05$ according to Duncan's Multiple Range Test. S- (No salinity), M- (No mycorrhiza), S+ (Plus salinity), M+ (Plus mycorrhiza), (Ri)-Rhizophagus irregularis, 0.00 (Plants died off).

Percentage AMF root colonization of C. maxima was significantly $(p=0.05)$ reduced in saline soil treatments of the test plants (Table 4$)$. However, inoculated saline soil treatment showed significant $(\mathrm{p}=0.05)$ increased in the \%AMF root colonization.

\section{Discussion}

Analysis of the saline and garden soils used in this study revealed significant $(\mathrm{p}=0.05)$ variations in their soil physico-chemical parameters. Significant $(\mathrm{p}=0.05)$ increase in parameters such as $\mathrm{pH}$, $\mathrm{EC}$ and $\mathrm{Ex} \mathrm{Na}^{+}$was observed in the saline soil while there was a decrease in organic carbon, total nitrogen and available phosphorus in saline soil. This observation is in line with the work of Miller ${ }^{18}$ who reported an increase in $\mathrm{pH}$ and $\mathrm{EC}$ in saline soils in New Jersey due to salt stress. Deleke ${ }^{19}$ also made similar findings as they observed an increase in $\mathrm{pH}, \mathrm{EC}$ and $\mathrm{Ex} \mathrm{Na}^{+}$in saline soils and a decrease in organic carbon, organic matter, total nitrogen and phosphorus in salinity influenced soils in Nigeria. Soil organic carbon content is influenced by two opposing factors: reduced plant inputs and reduced rates of decomposition. ${ }^{20}$ 
Table 4 Arbuscular mycorrhizal fungi (AMF) colonization of C. maxima grown in saline soil

\begin{tabular}{llllll}
\hline $\begin{array}{l}\text { Non-inoculated } \\
\text { treatment }\end{array}$ & $\begin{array}{l}\text { Root } \\
\text { colonization (\%) }\end{array}$ & $\begin{array}{l}\text { Mycorrhizal } \\
\text { dependency (\%) }\end{array}$ & $\begin{array}{l}\text { Inoculated } \\
\text { treatments }\end{array}$ & $\begin{array}{l}\text { Root } \\
\text { colonization (\%) }\end{array}$ & $\begin{array}{l}\text { Mycorrhizal } \\
\text { dependency (\%) }\end{array}$ \\
\hline S-M- & 0 & 0 & $\mathrm{~S}+\mathrm{M}+(\mathrm{Ri})$ & $* 20.34^{\mathrm{d}}$ & $100.00^{\mathrm{a}}$ \\
S+M- & 0 & 0 & $\mathrm{~S}-\mathrm{M}+(\mathrm{Ri})$ & $45.45^{\mathrm{b}}$ & $13.87^{\mathrm{d}}$
\end{tabular}

*Mean of three replicates. a Means within of each column followed by different letters are significantly different at $\mathrm{p}=0.05$ according to Duncan's Multiple Range Test. S- (No salinity), M- (No mycorrhiza), S+ (Plus salinity), M+ (Plus mycorrhiza), (Ri)-Rhizophagus irregularis.

Salt stress significantly $(\mathrm{p}=0.05)$ reduced the total photosynthetic pigments contents in C. maxima in both mycorrhizal and nonmycorrhizal saline treated plants. Non-mycorrhizal plants in saline soil treatments were more severely affected than $C$. maxima inoculated with $R$. irregularis. Amira ${ }^{21}$ also recorded decrease in chlorophyll 'a', 'b', and total chlorophyll in $V$. faba exposed to saline stress. Also, Tort $^{22}$ reported that exposure of Hordeum vulgare L. (barley) to different salinity levels 0,120 , and $240 \mathrm{~mm}$ of $\mathrm{NaCl}$ results in the reduction in chlorophyll ' $a$ ', chlorophyll ' $b$ ' and total chlorophyll content. Under stress conditions, the photosynthetic activity of the plant is often affected due to the alteration in the level and activity of various photosynthetic enzymes such as rubisc ${ }^{23}$ sucrose phosphate synthase and fructose-1,6-bisphosphatase. ${ }^{24}$ and PEP carboxylase..$^{25}$ All these could have led to reduction in photosynthesis and subsequent lower biomass accumulation resulting in growth reduction in saline soil grown plants. The influence of AMF on photosynthetic pigments of AMF inoculated plants growing under salinity stress conditions has been reported by several researchers. ${ }^{26-29}$ The increased rate of photosynthesis in AMF-colonized plants under salinity stress has been correlated with lower intercellular $\mathrm{CO}_{2}$ concentration in mycorrhizal plants, since the higher photosynthetic capacity increases water use efficiency for the assimilation of more carbon per unit water transpiration. ${ }^{26}$

The mineral (N, P, K, Mg and $\mathrm{Ca}$ ), leaf relative water content and biomass yield of $C$. maxima were significantly $(\mathrm{p}=0.05)$ reduced in saline soil treatments in this study, while foliar uptake and accumulation of $\mathrm{Na}^{+}$was significantly $(\mathrm{p}=0.05)$ increased in saline soil treatments than in non-saline treatments. Comparing the influence of $\mathrm{Na}^{+}$foliar uptake on minerals, leaf relative water content and biomass yield, it was observed that $\mathrm{Na}^{+}$accumulation had negative effects on the minerals, leaf relative water content and biomass yield of $C$. maxima (Figure 3) (Figure 4). This observation agrees with the work of Robert et al., ${ }^{30}$ who reported that exposure to $\mathrm{NaCl}$ injures plants in part through lowered soil water potential and the ensuing osmotic stress, but ultimately it may be more injurious via direct toxicity of $\mathrm{Na}^{+}$ions . Ullah et al., ${ }^{31}$ reported that irrigation of tomato plants with seawater increased the uptake of sodium chloride and decreased the uptake of $\mathrm{P}$ and $\mathrm{Fe}$. Increased concentration of $\mathrm{Na}^{+}$and $\mathrm{Cl}^{-}$in soil solution competes with the uptake of vital ions such as $\mathrm{Ca}^{+2}, \mathrm{P}, \mathrm{K}^{+}, \mathrm{Mg}^{+2}$, and $\mathrm{N}$ and alters the ideal salt ratios in the soil solution, therefore affecting plant nutrient acquisition and restricting plant growth and biomass. In this study, it was also observed that the minerals composition of $C$. maxima under saline and non-saline treatments was significantly increased with AMF $R$. irregularis inoculation. A higher $\mathrm{N}, \mathrm{P}, \mathrm{K}, \mathrm{Mg}$ and $\mathrm{Ca}$ concentration in mycorrhizal than non-mycorrhizal plants can favourably alleviate the toxic effects of $\mathrm{NaCl}$ by inducing a higher $\mathrm{K}^{+} /$ $\mathrm{Na}^{+}$rate leading to salt adaptation. ${ }^{32}$ Cantrell ${ }^{33}$ reported increased $\mathrm{N}$, $\mathrm{P}, \mathrm{K}, \mathrm{Mg}$ and $\mathrm{Ca}$ uptake in mycorrhizal lettuce.

AMF root colonization (MC) of C. maxima was significantly $(\mathrm{p}=0.05)$ reduced in saline soil treatments when compared to nonsaline treatments. This is in agreement with earlier studies reporting that addition of salt to soil inhibits hyphal growth, which subsequently reduces the spread of mycorrhizal colonization. ${ }^{32,34}$ It was also observed in this study that mycorrhizal dependency (MD) varied with saline treatments. Root colonization of C. maxima by $R$. irregularis showed great dependency of these plants on the AMF when compared to the purely saline non-mycorrhizal treatment. This corroborates the work of Beltrano et al., ${ }^{35}$ who demonstrated the favourable relationship between pepper and $G$. intaradices ( $R$. irregularis), and shows that when roots were associated with AM fungi, the detrimental effect of the salinity stress decreased significantly. Taken together, although salinity reduced mycorrhizal colonization, the dependency of pepper plants on mycorrhizal fungi was high. ${ }^{35-41}$

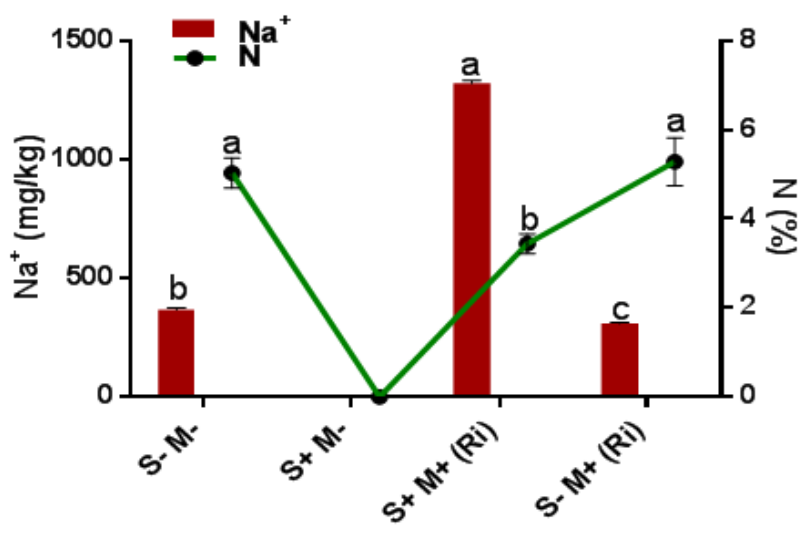

Treatments

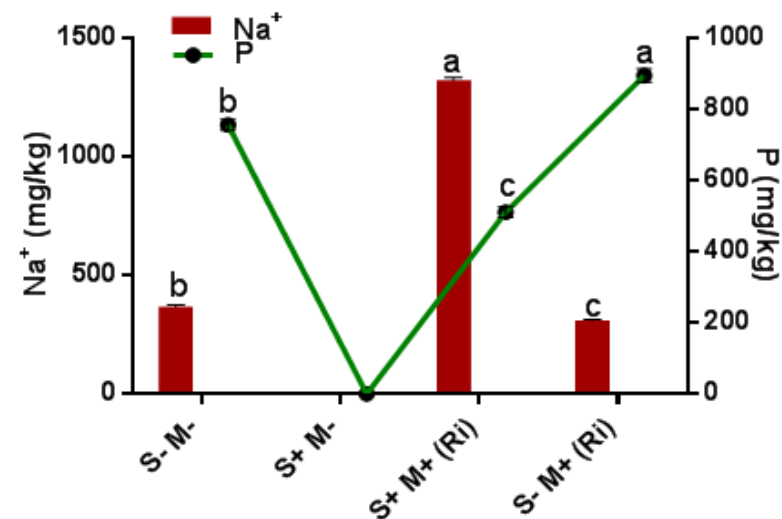

Treatments

Figure 3 Influence of AMF inoculation on foliar $\mathrm{Na}^{+}$uptake in $\mathrm{C}$. maxima as it affects its $\mathrm{N}$ and $\mathrm{P}$ content. 


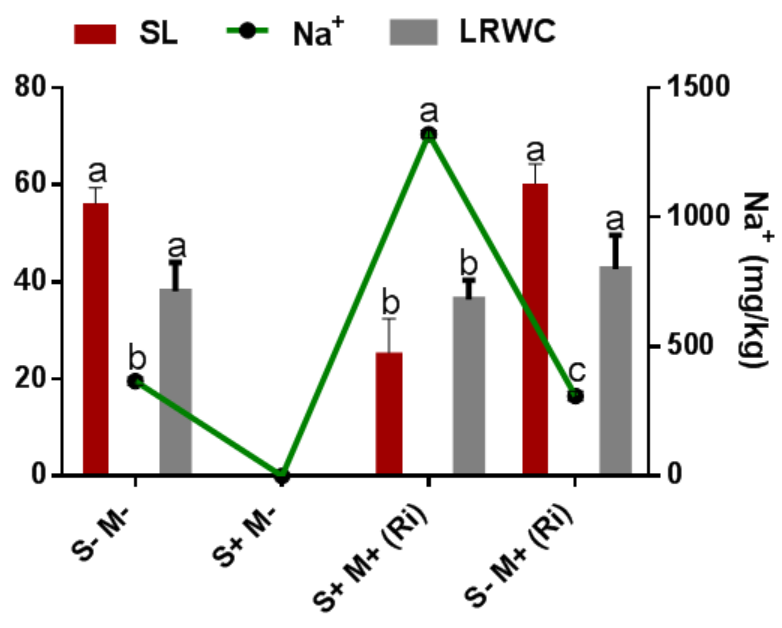

\section{Treatments}

Figure 4 Influence of AMF inoculation on foliar $\mathrm{Na}^{+}$uptake in C. maxima as it affects its Shoot length (SL) and Leaf relative water content (LRWC) content.
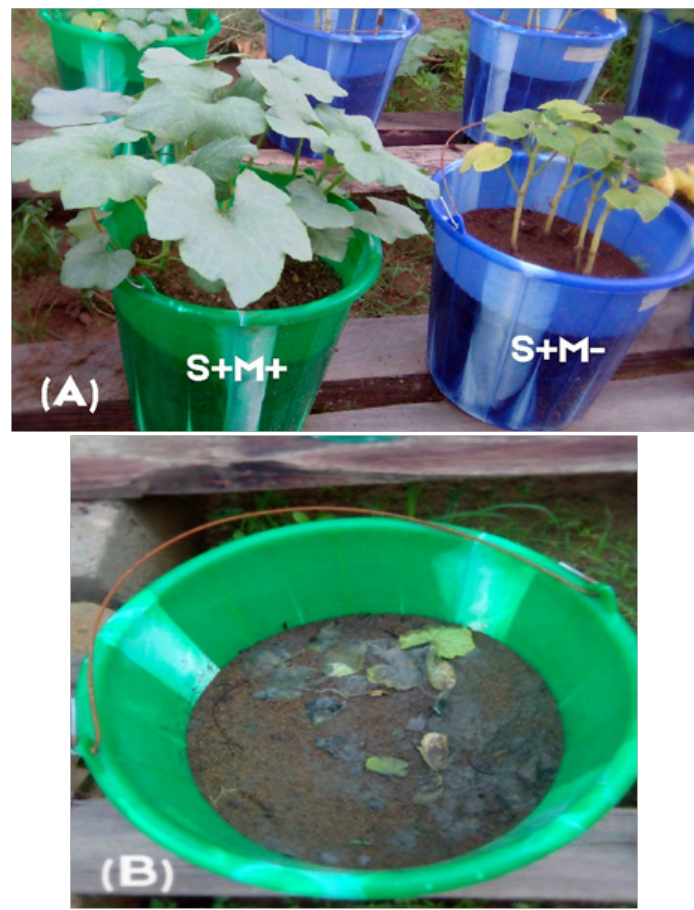

Figure 5 (A) Shows growth response of Rhizophagus irregularis inoculated saline treated $(\mathrm{S}+\mathrm{M}+)$ and uninoculated saline treated $(\mathrm{S}+\mathrm{M}-)$ C. maxima six (6) weeks after planting (B) uninoculated saline treated ( $S+M-)$ C. maxima dies off twelve (12) weeks after planting; soil shows hard surface crusting which results in poor soil aeration, porosity and low microbial activities.

\section{Conclusion}

The accumulation of salts in the soil is one of the major threats facing crop yield and production worldwide. It has been estimated that about $7 \%$ of the earth's land is exposed to high soil salinity levels. Results of this research revealed that salt stress negatively affected the physicochemical properties of the saline soil when compared to the garden soil, thus resulting in excessive uptake of $\mathrm{Na}^{+}$and subsequently; negative effects on photosynthetic pigments, minerals contents, relative leaf water content (RLWC), shoot length, dry weight, mycorrhizal colonization and dependency of C. maxima. The effects of mycorrhizal symbiotic association on C. maxima showed improvements on the growth and physiology of C. maxima. Using different mechanisms $C$. maxima by itself or in association with arbuscular mycorrhizal fungi ( $R$. irregularis) can tolerate or survive soil salinity. However, symbiotic association of the fungus $R$. irregularis with roots of $C$. maxima gives the plant the ability to resist the stress as a result of morphological and physiological vicissitudes and improved vigour/water content, adjusted rate of $\mathrm{K}^{+} / \mathrm{Na}^{+}$, extensive network of the mycorrhizal plant roots and enhanced nutrient uptake are all among the processes that made the mycorrhizal inoculated plant to survive under severe salt stress conditions.

\section{Acknowledgments}

None.

\section{Conflicts of interest}

The author declares there is no conflicts of interest.

\section{References}

1. Saxena B, Giri B. Shukla K. Arbuscular mycorrhizal fungi and tolerance of salt stress in plants. In: QS Wu, editor. Arbuscular mycorrhizas and stress tolerance of plants. Germany; 2017.

2. Nasim G. The role of arbuscular mycorrhizae in inducing resistance in drought and salinity stress in crops. Plant adaptation and phytoremediation. 2010;1:119-141.

3. Ebrahim KE. Role of arbuscular mycorrhizal fungi in fighting soil salinity. 2014.

4. Zhu JK. Plant salt tolerance. Trends Plant Sci. 2001;6(2):66-71.

5. Kumar A, Dames JF, Gupta A. Current developments in arbuscular mycorrhizal fungi research and its role in salinity stress alleviation: a biotechnological perspective. Crit Rev Biotechnol. 2015;35(4):461-474.

6. Evelin H, Kapoor R, Giri B. Arbuscular mycorrhizal fungi in alleviation of salt stress: a review. Annals of Botany. 2009;104:1263- 1280.

7. Smith SE. Read DJ. Mycorrhizal symbiosis. 2008

8. Nielsen KB, Kjoller R, Olsson PIA, et al. Colonisation and molecular diversity of arbuscular mycorrhizal fungi in the aquatic plants Littorella uniflora and Lobelia dortmanna in Southern Sweden. Mycological Research. 2004;108:616-625.

9. Talaat NB, Abdallah AM. Response of faba bean (Vicia faba L.) to dual inoculation with Rhizobium and VA mycorrhiza under different levels of $\mathrm{N}$ and P fertilization. Journal of Applied Sciences Research. 2008;4:1092-1102.

10. Villasenor IM, Bartolome ALO. Microbiological and pharamcological studies on extracts of Cucurbita maxima. Phytotherapy Research. 1995;9(5):376-378.

11. Ngwerume FC, Grubben GJH. Cucurbita maxima Duchesne: Record from PROTA. In: GJH Grubben, OA Denton, editors. Plant resources of tropical Africa (PROTA). 1786.

12. Kruger M, Claudia K, Christopher W, et al. Phylogenetic Reference Data for Systematics and Phylotaxonomy of Arbuscular Mycorrhizal Fungi from Phylum to Species Level. New Phytol. 2012;193(193):970-984.

13. AOAC. Official Methods of Analysis. 10th and 17th ed. 2005. 
14. Hiscox JD, Israelstam GF. A method for the extraction of chlorophyll from leaf tissue without maceration. Canadian Journal of Botany. 1979;57(12):1332-1334.

15. AOAC. Official Methods of Analysis. 17th ed. 2003.

16. Walker C. A simple blue staining technique for arbuscular mycorrhizal and other root-inhibiting fungi. Inoculum, 2005;56(4):68-69.

17. Giovannetti M, Mosse B. An evaluation of techniques for measuring vesicular arbuscular mycorrhizal infection in roots. New Phytologist. 1980;84(3):489-500

18. Miller RW, Gardiner DT. Soils in our environment. 9th ed. 2001.

19. Dedeke OA, Akomolafe GF. Influence of salinity on soil chemical properties and surrounding vegetation of awe salt mining site, Nasarawa State, Nigeria. African Journal of Environmental Science and Technology. 2013;7(12):1072-1075.

20. Garg N, Manchanda G. Effect of arbuscular mycorrhizal inoculation of salt-induced nodule senescence in Cajanus cajan (pigeon pea). Journal of Plant Growth Regulation. 2008;27:115-124.

21. Amira MS, Abdul Q. Effect of salt stress on plant growth and metabolism of bean plant Vicia faba (L.). Journal of the Saudi Society of Agricultural Sciences. 2010;10(1):7-15.

22. Tort N, Turkyilmaz B. A physiological investigation on the mechanisms of salinity tolerance in some barley culture forms. Journal of Food Security. 2004;27:1-16.

23. Valentine AJ, Mortimer PE, Lintnaar M, et al. Drought responses of arbuscular mycorrhizal grapevines. Symbiosis. 2006;41(3):127-133.

24. Ghosh S, Bagchi S, Majumder AL. Chloroplast fructose-1, 6-bisphosphatase from Oryza differs in salt tolerance property from the porteresia enzyme and is protected by osmolytes. Plant Science. 2001;160(6):1171-1181.

25. Abdel LAA. Phosphoenol pyruvate carboxylase activity of wheat and maize seedlings subjected to salt stress. Australian Journal of Basic and Applied Science. 2008;2(1):37-41.

26. Sheng $\mathrm{M}$, Tang $\mathrm{M}$, Chan $\mathrm{H}$, et al. Influence of arbuscular mycorrhizae on photosynthesis and water status of maize plants under salt stress. Mycorrhiza. 2008;18(6-7):287-296.

27. Zuccarini P, Okurowska P. Effects of mycorrhizal colonization and fertilization on growth and photosynthesis of sweet basil under salt stress. Journal of Plant Nutrition. 2008;31(3):497-513.

28. Hajiboland R, Aliasgharzadeh N, Laiegh SF, et al. Colonization with arbuscular mycorrhizal fungi improves salinity tolerance of tomato
(Solanum lycopersicum L.) plants. Plant and Soil. 2010;331(1-2):313327.

29. Wu QS, Zon YN, Liu W. Alleviation of salt stress in citrus seedlings inoculated with mycorrhiza: changes in leaf antioxidant defense systems. Plant Soil Environment. 2010;56:470-475.

30. Robert MA, Heather DT, Arnold MS. Arbuscular mycorrhizal symbiosis and osmotic adjustment in response to $\mathrm{NaCl}$ stress: a meta-analysis. Front Plant Sci. 2014;5:562.

31. Ullah SM, Gerzabek MH, Soja G. Effect of seawater and soil salinity on ion uptake, yield and quality of tomato (fruit). Die Bodenkultur. 1994;45:227-237.

32. Evelin H, Giri B, Kapoor R. Contribution of Glomus intraradices inoculation to nutrient acquisition and mitigation of ionic imbalance in NaCl-stressed Trigonella foenum-graecum. Mycorrhiza. 2012;22(3):203217.

33. Cantrell IC, Linderman RG. Preinoculation of lettuce and onion with VA mycorrhizal fungi reduces deleterious effects of soil salinity. Plant and Soil. 2001;233(2):269-281.

34. Jahromi F, Aroca R, Porcel R, et al. Influence of salinity on the in vitro development of Glomus intraradices and on the in vivo physiologica and molecular responses of mycorrhizal lettuce plants. Microb Ecol. 2008;55(1):45-53.

35. Beltrano J, Ruscitti M, Arango MC, et al. Effects of arbuscular mycorrhiza inoculation on plant growth, biological and physiological parameters and mineral nutrition in pepper grown under different salinity and p levels. Journal of Soil Science and Plant Nutrition. 2013;13 (1):123-141.

36. Akoroda MO. Ethnobotany of Telfairia occidentalis (Cucurbitaceae) among Igbos of Nigeria. Economic Botany. 1990;44(1):29-39.

37. Badifu GIO. Food potentials of some unconventional oil seeds grown in Nigeria - a brief review. Plant Foods Hum Nutr. 1993;43(3):211-224.

38. Giami SY. Effect of germination on bread-making properties of wheatfluted pumpkin (Telfairia occidentalis) seed flour blends. Plant Foods for Human Nutrition. 2003;58(3):1-9.

39. Hildebrandt U, Janetta K, Ouziad F, et al. Arbuscular Mycorrhizal Colonization of Halophytes in Central European Salt Marshes. Mycorrhiza. 2001;10(4):175-183.

40. Nwanna EE, Oboh G. Antioxidant and hepatoprotective properties of Telfairia occidentalis leaf (fluted pumpkin). Pak J Biol Sci. 2007;10(16):2682-2687.

41. US Department of Agriculture. Research database. Bibliography on salt tolerance. 2008. 